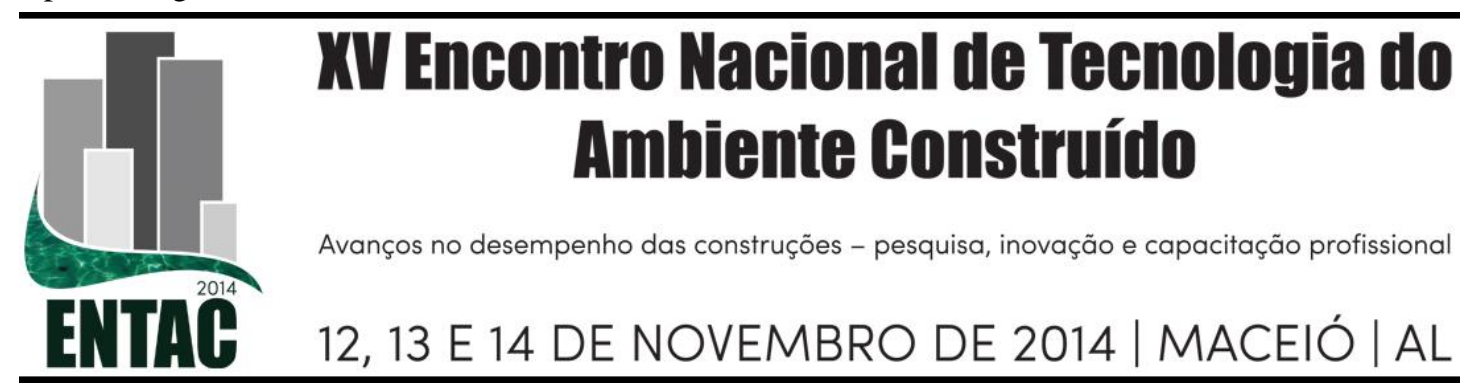

\title{
AVALIAÇÃO DE TIJOLOS DE ADOBE COM ADIÇÃO DE CINZAS E FIBRAS DO COCO
}

\author{
COSTA, Heloina Nogueira (1); PINHEIRO, Levi Teixeira (2); MENEZES, \\ Francisco Charlys Moreira (3); CABRAL, Antonio Eduardo Bezerra (4) \\ (1) UFC, e-mail: heloinan@ hotmail.com, (2)UFC, levi.teixeira@terraambiente.com.br, (3) Eng Civil, \\ charlysmenezes50@hotmail.com (4) UFC, e-mail: eduardo.cabral@ufc.br,
}

\begin{abstract}
RESUMO
O adobe é uma das primeiras técnicas construtivas conhecidas pela humanidade, apesar de antiga, ainda é utilizada na produção de habitações populares em diversos lugares do mundo, principalmente em zonas rurais, onde o acesso a materiais de construção e novas tecnologias é restrito. A simplicidade de execução e o baixo custo são suas principais vantagens para comunidades distantes dos centros urbanos. Ainda que, suas vantagens técnicas sejam limitadas em relação a outros materiais, são capazes de atender as necessidades do meio rural, por exemplo, o isolamento térmico, acústico, resistência ao fogo e sustentabilidade, pois não gera resíduo e não necessita da queima de madeira em seu processo de fabricação. A técnica apresenta desvantagens, principalmente, quando sujeita às intempéries, como chuvas e raios solares. Portanto, o objetivo geral deste trabalho é verificar o desempenho de tijolos de adobe com adições de cinzas de combustão de carvão mineral (CCCM) e fibras de coco, quanto à resistência à compressão e à durabilidade na presença de água. A parte experimental foi dividida em três etapas: caracterização dos materiais; produção dos tijolos; e avaliação dos mesmo por meio do ensaio de resistência à compressão e de durabilidade. Foram moldados tijolos de adobe com adição de 5\%, 10\%, $15 \%$ e $20 \%$ de CCCM e tijolos com adição de $1 \%$, $3 \%$ e $5 \%$ de fibras do coco. Os resultados do ensaio de resistência à compressão apontam melhor desempenho dos tijolos com adição de CCCM, já no ensaio de durabilidade na presença de água, os tijolos com fibras do coco apresentam melhores resultados.
\end{abstract}

Palavras-chave: Adobe, cinza de combustão de carvão mineral, fibras do coco.

\begin{abstract}
The adobe is one of the first building techniques known to mankind, and although old, is still used in the production of affordable housing in many places in the world, especially in rural areas, where access to building materials and new technologies is restricted. The simplicity of implementation and low cost are key benefits to communities far from urban centers. Although, technical advantages are limited compared to other materials, are able to meet the needs of rural areas, for example, thermal, acoustic, fire resistance and insulation sustainability because it does not generate waste and does not require the burning of wood in its manufacturing process. The technique has disadvantages, especially when subjected to the weather, such as rain and sunlight. Therefore, the objective of this work is to verify the performance of adobe blocks with additions of ash from combustion of coal (CCCM) and coconut fiber, as the compressive strength and durability in the presence of water. The experimental part was divided into three steps: characterization of materials; production of the blocks; and evaluation of the same through the test of compressive strength and durability. Adobe blocks with addition of 5\%, 10\%, 15\% and $20 \%$ and KCCM blocks with addition of 1\%, 3\% and $5 \%$ coconut fibers were molded. The test results of the compressive strength of the blocks indicate better performance with KCCM addition, since the durability test in the presence of water, the blocks with coconut fibers have the best results.
\end{abstract}

Keywords: Adobe, ash combustion of coal, coconut fibers. 


\section{INTRODUÇÃO}

A construção com terra é uma técnica construtiva remota, apontada como uma das primeiras formas de construção que a humanidade conheceu, que se utiliza de um material abundante em todo planeta (FREIRE, 2003). Ainda hoje, são várias as técnicas construtivas em terra usadas em todo o mundo, como por exemplo: taipa de pilão, taipa de mão (ou pau-a-pique), terra ensacada, adobe ou BTC (bloco de terra comprimida). Em meio às preocupações atuais voltadas para sustentabilidade, a técnica milenar do adobe ressurge como uma opção para construção civil em locais distantes dos centros urbanos (CORRÊA et al, 2006).

No interior do Ceará, o adobe ainda é utilizado como técnica construtiva, na região norte do estado, nas cidades de Viçosa do Ceará, Camocim, Sobral e entorno, somando cerca de 30 municípios, onde existem famílias na zona rural que habitam em casas com mais de 50 anos construídas em adobe. Segundo Carvalho (2012), estas cidades do interior do estado conservaram sistemas construtivos puros ao longo dos anos, quase sem intervenções de sistemas construtivos diferentes.

O adobe se apresenta como um material construtivo sustentável e de baixo custo. Porém, o seu uso, nas construções convencionais brasileiras, foi abandonado por apresentar algumas desvantagens, principalmente, na presença de água.

Por outro lado, há uma série de técnicas que foram desenvolvidas para melhorar o desempenho dos adobes. Freire (2003) recomenda o uso de estabilizantes naturais e industrializados (produtos e subprodutos) como pozolanas, fibras vegetais, betume, gesso, cinzas de madeira, entre outros. Nesse contexto, o objetivo deste trabalho é analisar o desempenho de blocos de adobe com a adição de cinzas de combustão de carvão mineral (CCCM) e fibras de coco, quanto à resistência à compressão e durabilidade na presença de água.

A CCCM e a fibra do coco são resíduos disponíveis na cidade de Fortaleza-CE, o primeiro em virtude da usina termoelétrica localizada na região metropolitana com capacidade de $365 \mathrm{MW}$ de geração de energia, que entrou em atividade em 2012, o segundo, devido ao alto consumo de coco verde na cidade, que ultrapassa $700 \mathrm{mil}$ unidades mensais.

\section{REFERENCIAL TEÓRICO}

\subsection{Adobe}

Segundo Oliveira (2003), o adobe é uma técnica tradicional de alvenaria, onde a principal matéria prima é a terra crua. O processo de fabricação do tijolo de adobe consiste em amassar a terra, deixar descansar por alguns dias e, ainda úmido, colocá-la em fôrmas, deixando-a secar ao sol. Atualmente, o tijolo também é feito com processo de secagem à sombra (CARVALHO, 2012).

A resistência à compressão dos tijolos de adobe é satisfatória para realização de construções com segurança do ponto de vista estrutural. Os estudos de Motta (2004) revelam que a resistência média do bloco é de $2 \mathrm{MPa}$. Esse valor é semelhante à resistência do tijolo cerâmico comum, o que mostra que o sistema é competitivo nesse aspecto. O tijolo de adobe apresenta também outras vantagens (FREIRE, 2003): simplicidade de execução, pois não há necessidade de mão de obra qualificada e de equipamentos específicos; custos de produção dos tijolos praticamente nulos, quando há barro disponível no local; não gera resíduo e não necessita da queima de madeira; permite um isolamento térmico e acústico; material resistente ao fogo. Apesar de 
apresentar tais qualidades, o adobe apresenta também desvantagens: a presença de água pode provocar a desintegração no material e falhas estruturais; apresenta altas taxas de contração/ expansão, o que leva ao aparecimento de fissuras, quando o material permanece exposto a condições climáticas variáveis; possui baixa resistência a abrasão; necessita de manutenção frequente.

Devido às desvantagens que o sistema apresenta foram desenvolvidas ao longo da história diversas técnicas para estabilizar o tijolo. Os estabilizantes foram divididos em estabilizantes naturais e industrializados (produtos e subprodutos). Os principais materiais utilizados como estabilizantes são: naturais - areia e argila, palhas e fibras vegetais, sumo de plantas, cinza de madeira, sangue fresco de bovino com cal e esterco de animal; Industrializados - cal, pozolanas, cimento Portland, gesso, silicato de sódio, entre outros (FREIRE, 2003).

\subsection{Cinza de Combustão de Carvão Mineral - CCCM}

Segundo Freire (2003), a calcinação do carvão mineral em caldeiras de leito fluidizado é bastante comum, especialmente na geração de energia termoelétrica.

A maior parte do carvão consumido atualmente em usinas termoelétricas é queimada em caldeiras de carvão pulverizado. Neste tipo de caldeira, mais de três quartos da cinza produzida é leve o bastante para ser arrastada com os gases de combustão (cinza leve ou volante), sendo na sua maior parte coletada por equipamentos de retenção, como precipitadores eletrostáticos. As cinzas remanescentes são densas o suficiente para não serem emitidas para a atmosfera e caem, no fundo da caldeira, fundidas em partículas maiores (cinza pesada ou residuária) (FUNGARO E SILVA, 2002).

Segundo a NBR 12653 (ABNT,2012), cinzas volantes são materiais finamente divididos, que resultam da combustão de carvão pulverizado ou granulado com atividade pozolânica. Conforme Mehta (1987), a composição química das cinzas volantes é determinada pelo tipo de carvão utilizado e pela quantidade de material incombustível presente no mesmo. Mais de $85 \%$ da maioria das cinzas volantes são formadas pelos elementos silício, alumínio, ferro, cálcio e magnésio. Ainda o mesmo autor afirma que a cinza volante exibe atividade pozolânica, pois contem silicatos de alumínio metaestáveis, que reagem com os íons de cálcio em presença de umidade, para formar silicatos de cálcio hidratado.

\subsection{Fibras do coco}

As fibras do coco são formadas de celulose, hemicelulose, lignina, pectina, cera e outras substâncias solúveis em água. O alto conteúdo de lignina permite que a degradação da fibra de coco ocorra mais lentamente que outras fibras vegetais (HEJAZI et al., 2012). A vantagem da fibra do coco em relação às demais fibras naturais é a sua maior durabilidade, pois em relação à resistência à tração e ao módulo de elasticidade esta apresenta-se em desvantagem, conforme o estudo de Motta e Agopyan (2007) que comparou fibras vegetais e industrializadas. O seu uso em compósito de terra já é uma prática advinda desde a antiguidade para evitar fissuras nos solos com alto teor de argila. Dentre as fibras mais utilizadas como reforço do adobe tem as de sisal, cânhamo, capim elefante, fibra de coco e fibra de bagaço de cana-de-açúcar (FREIRE, 2003). 


\section{MATERIAIS E MÉTODOS}

\subsection{Solo}

O solo utilizado na produção dos blocos de adobe foi coletado de uma escavação no campus Pici da Universidade Federal do Ceará - latitude: $3^{\circ} 44^{\prime 2} 27.97^{\prime \prime}$ S/ longitude 38 34"31.10" O. O material foi preparado para os ensaios seguindo as orientações da NBR 6457 (ABNT, 1986). Na tabela 1 são apresentados os resultados da caracterização do solo.

Tabela 1 - Características físicas da CCCM

\begin{tabular}{ll|c}
\hline \multicolumn{1}{c|}{ Ensaio } & \multicolumn{1}{c}{ Norma } & Resultado \\
\hline Densidade real $\left(\mathrm{Kg} / \mathrm{dm}^{3}\right)$ & ME 093 (DNER, 1994) & 2,57 \\
\hline Massa específica aparente seca $\left(\mathrm{g} / \mathrm{cm}^{3}\right)$ & NBR 7182 (ABNT, 1986) & 1,850 \\
\hline Umidade Ótima (\%) & NBR 7182 (ABNT, 1986) & 16 \\
\hline Limite de Liquidez (\%) & NBR 6459 (ABNT, 1984) & 27 \\
\hline Limite de Plasticidade (\%) & NBR 7180 (ABNT, 1994) & 14 \\
\hline Índice de plasticidade (\%) & NBR 7180 (ABNT, 1994) & 13 \\
\hline
\end{tabular}

Fonte: Autores, 2013

A granulometria foi realizada conforme a NBR 7181 (ABNT, 1984). A curva granulométrica é apresentada na figura 1.

Figura 1 - Curva granulométrica

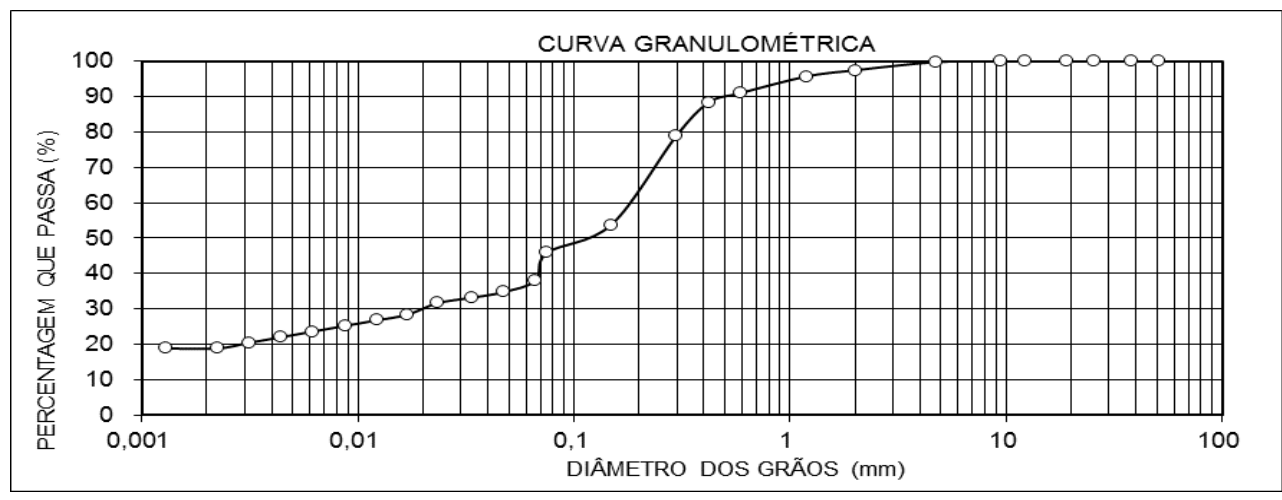

Fonte: Autores, 2013.

A curva granulométrica apresenta a composição do solo nas seguintes proporções: $53 \%$ de areia, $22 \%$ de argila e $24 \%$ de silte. O solo apresenta uma aproximação razoável das proporções recomendadas e se caracteriza como solo adequado para confecção de tijolos de adobe. Martinez (1979) define a composição ideal para adobe um material com $20 \%$ de argila e $40 \%$ a $55 \%$ de areia. Hernandez et al. (1983) definem a porcentagem ideal de areia para os adobes próxima de $50 \%$, silte de $30 \%$ e argila, $20 \%$.

\subsection{Cinza de Combustão de Carvão Mineral -CCCM}

A CCCM é originária da usina Termoelétrica Energia Pecém, localizada na cidade de São Gonçalo do Amarante-CE. Na tabela 2 são apresentadas as características físicas da CCCM. 
Tabela 2 - Características físicas da CCCM

\begin{tabular}{llc}
\hline \multicolumn{1}{c}{ Ensaio } & \multicolumn{1}{c}{ Norma } & Resultado \\
\hline Dimensão Máxima Característica (mm) & NBR NM 248 (ABNT, 2001) & 0,150 \\
\hline Módulo de finura & NBR NM 248 (ABNT, 2001) & 0,252 \\
\hline Umidade (\%) & NBR NM 24 (ABNT, 2003) & 0,6 \\
\hline Massa específica (g/cm3) & NBR NM 23 (ABNT, 2001) & 2,33 \\
\hline Índice de atividade pozolânica (\%) & NBR 5752 (ABNT,2012) & 98,95 \\
\hline
\end{tabular}

Fonte: Nobre et al, 2013.

Observa-se que a CCCM apresenta índice de atividade pozolânica superior a $75 \%$, que de acordo com NBR 5752 (ABNT,2012) é considerado material pozolânico. Tal característica foi comprovada com o ensaio de difração de raios X. A figura 2 apresenta o difratograma de raios $\mathrm{X}$ da CCCM.

Figura 2 - Difratograma de raios $\mathrm{X}$ da $\mathrm{CCCM}$

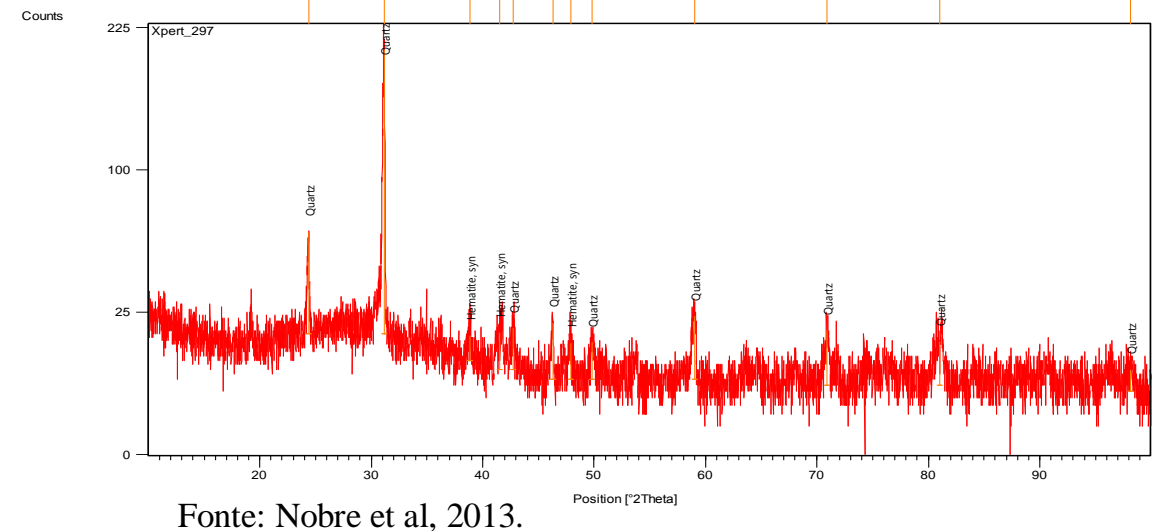

O difratograma apresenta um halo amorfo característico de materiais pozolânicos e compostos cristalinos, identificados como quartzo e hematita. A composição química da CCCM foi obtida através de espectrometria de fluorescência de raios X. O resultado da análise química é mostrado na tabela 3.

Tabela 3 - Composição química da CCCM

\begin{tabular}{cccccccc}
\hline Elemento & $\begin{array}{c}(\boldsymbol{\%}) \\
\text { Massa }\end{array}$ & Elemento & $\begin{array}{c}(\boldsymbol{\%}) \\
\text { Massa }\end{array}$ & Elemento & $\begin{array}{c}(\boldsymbol{\%}) \\
\text { Massa }\end{array}$ & Elemento & $\begin{array}{c}(\%) \\
\text { Massa }\end{array}$ \\
\hline $\mathrm{Si}$ & 42,906 & $\mathrm{Fe}$ & 27,067 & $\mathrm{Al}$ & 12,029 & $\mathrm{Ca}$ & 7,2544 \\
\hline $\mathrm{K}$ & 5,4758 & $\mathrm{Ti}$ & 2,3774 & $\mathrm{~S}$ & 1,5991 & $\mathrm{Sr}$ & 0,3103 \\
\hline $\mathrm{Cl}$ & 0,3043 & $\mathrm{Mn}$ & 0,2417 & $\mathrm{Zn}$ & 0,1640 & $\mathrm{Cr}$ & 0,1365 \\
\hline $\mathrm{Ni}$ & 0,1347 & & & & & & \\
\hline
\end{tabular}

Fonte: Nobre et al, 2013.

Os elementos silício, ferro e alumínio representam $82 \%$ da composição da amostra, os demais elementos somam $18 \%$ do total.

\subsection{Fibras do coco}

As fibras de coco foram cedidas pela unidade de beneficiamento de casca do coco verde da EMPRAPA-CE. Para obter informações sobre a forma das fibras, uma amostra foi analisada através microscopia ótica para obtenção do diâmetro e o comprimento foi 
medido por paquímetro. Na figura 4 apresenta-se imagens da microscopia ótica das fibras.

Figura 3 - Microscopia ótica das fibras do coco

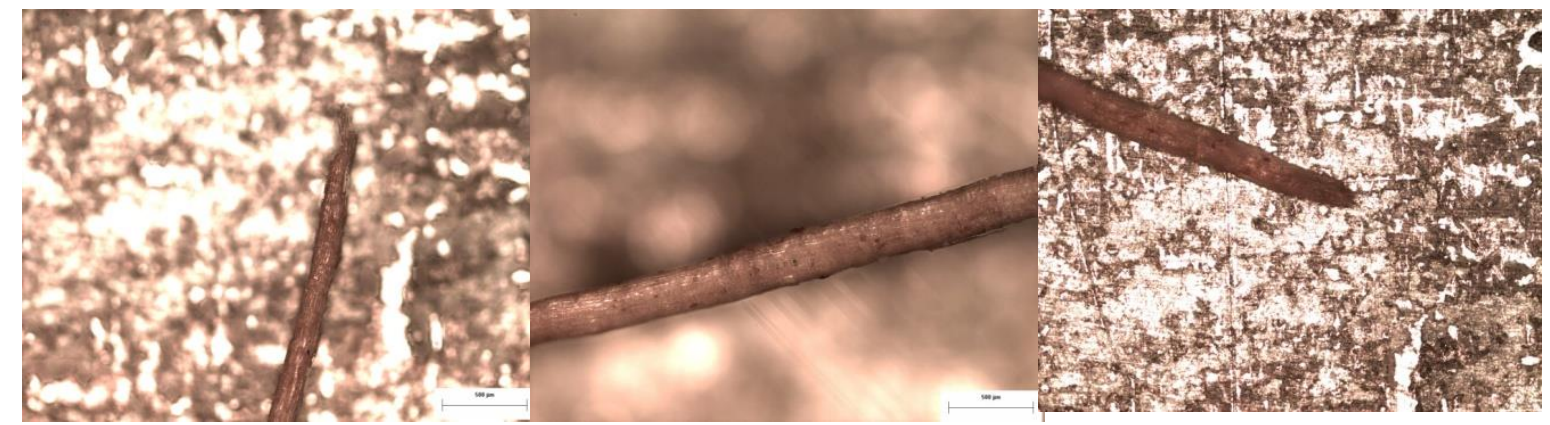

Fonte: Autores, 2013

Conforme a figura 4 foi observada diversas variações do diâmetro ao longo do seu comprimento, com isso, o índice de forma (divisão do comprimento da fibra pelo seu diâmetro) se torna variável. Não foi possível obter uma relação linear entre diâmetro e comprimento.

A massa específica da fibra do coco é igual a $0,97 \mathrm{~g} / \mathrm{cm}^{3}$, obtido através da NBR NM 52 (ABNT,2002), realizando-se adaptações para este material. A realização do ensaio seguiu a seguinte ordem de procedimentos: 1) selecionou-se a fibra seca cortando-a em tamanhos pequenos de aproximadamente $4 \mathrm{~cm}$; 2) pesou-se duas porções de fibra com massa de $10 \mathrm{~g}$; 3) inseriu as amostras em dois frascos distintos e pesou-se. Depois deixou-se durante $16 \mathrm{~h}$ no frasco em repouso na água; 4) retirou-se a fibra do frasco para secá-la em estufa à $(105 \pm 5){ }^{\circ} \mathrm{C}$ até massa constante $( \pm 0,1 \mathrm{~g})$. Foi resfriado à temperatura ambiente em dessecador e pesado novamente.

\subsection{Fabricação dos tijolos de adobe}

O processo de fabricação dos tijolos de adobe foi realizado manualmente, segundo a metodologia indicada por Carvalho (2012), com seguinte sequência: confecção das fôrmas; amassamento da terra; preparação e moldagem do material; desmoldagem dos tijolos; processo de secagem.

As formas foram executadas de madeira sem fundo com fórmica no seu interior para facilitar a desforma nas dimensões de 0,30 $\mathrm{m}$ de comprimento, 0,15 $\mathrm{m}$ de largura e 0,08 $\mathrm{m}$ de altura. Foram moldados blocos com adição de CCCM com os teores de 5\%, 10\%, $15 \%$ e $20 \%$ em volume. Os blocos com adição de fibras do coco foram moldados com os teores de adição de $1 \%, 3 \%$ e 5\%, também em volume. Os percentuais utilizados foram determinados com base em experimentos de Freire (2003) com adição destes materiais em compostos cimentícios.

\subsection{Ensaio de resistência à compressão}

A verificação de resistência à compressão foi adaptada da norma utilizada para tijolos de solo- cimento para alvenaria NBR 8492 (ABNT, 2012). Foram rompidos dois corpos de prova para cada traço no $24^{\circ}$ dia após sua fabricação.

\subsection{Ensaio de durabilidade na presença de água}

O ensaio de durabilidade foi realizado para analisar o comportamento do tijolo de adobe perante exposição à chuva durante um determinado período. Baseou-se no método 
desenvolvido por Ferreira e Silva (2009), que expõe os tijolos à chuva por determinado período de tempo. Neste trabalho esse processo foi acelerado.

O ensaio se propõe a simular o efeito da chuva durante um dia sobre o adobe. Para isso obteve-se dados da estação pluviométrica da Funceme - posto do Pici, dos últimos 40 meses, chegando ao valor de 3,7 mm de precipitação diária (FUNCEME, 2013). Com os dados da vazão de um chuveiro comum e a área do bloco calculou-se tempo necessário para o chuveiro gerar o volume de água correspondente, sendo igual a 27,29 segundos. $\mathrm{O}$ equipamento para simular a chuva consiste em um chuveiro suspenso ligado a uma mangueira. Aliado a este, tem-se um aparador para o tijolo, feito com uma tela metálica, este serve para permitir que o barro carreado pela água não se acumule sob o bloco.

\section{Figura 4 - Ensaio de durabilidade}

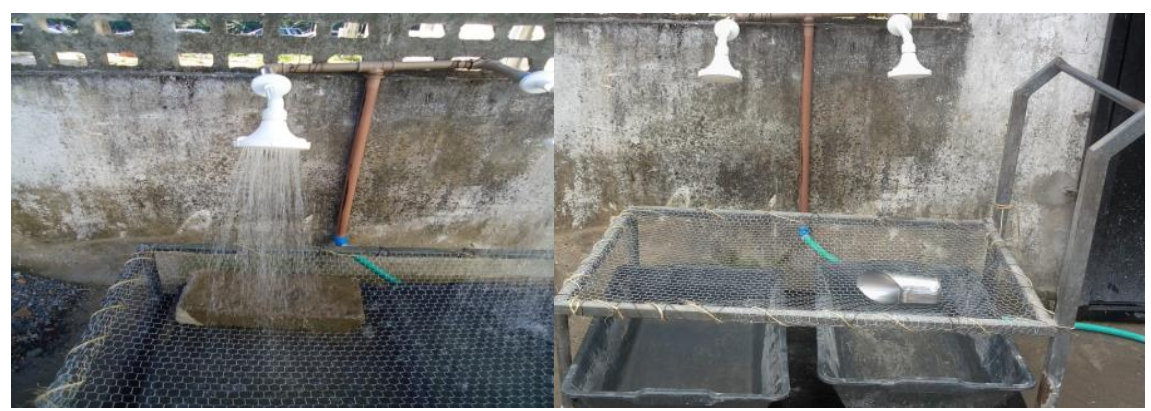

Fonte: Autores, 2013

Após o equipamento montado, o volume e o tempo de água calculado, separou-se dois blocos de cada traço e colocou-os na estufa durante 24 horas. Os blocos secos são pesados e colocados sobre a tela, então liga-se o chuveiro. Após o tempo previsto no equipamento, os blocos são colocados em estufa por 24 horas. Por fim são pesados novamente. Com a diferença de massa dos tijolos pode-se analisar quanto cada tijolo perdeu em massa.

\section{RESULTADOS}

\subsection{Resistência à compressão}

Os resultados obtidos no ensaio são apresentados no gráfico da figura 5.

Figura 5 - Gráfico dos resultados do ensaio de resistência à compressão

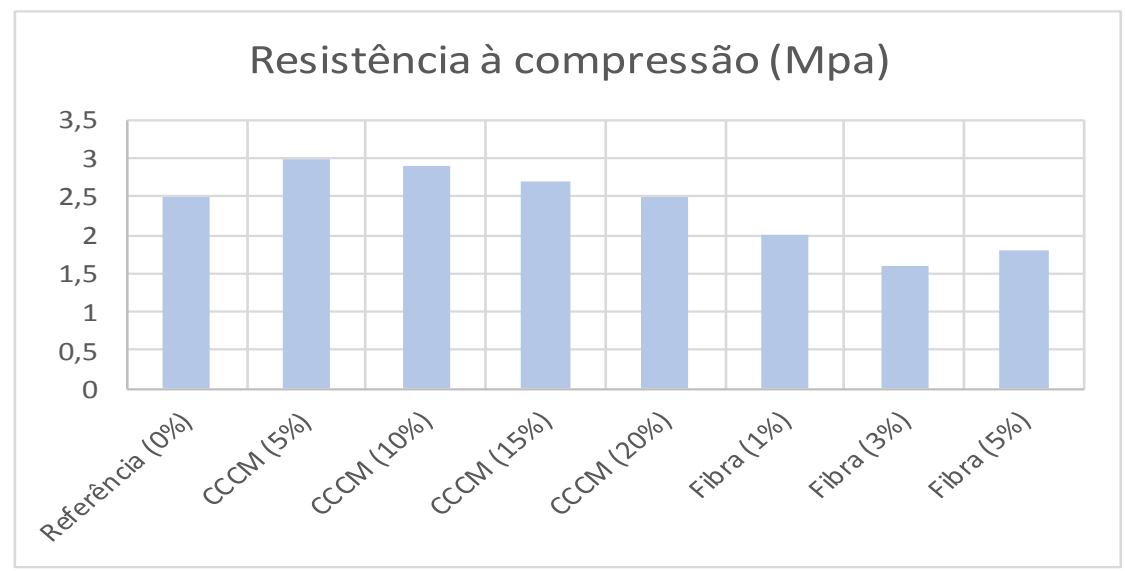

Fonte: Autores, 2013.

A NBR 8492 (ABNT, 2012) estipula que a média de resistência à compressão dos tijolos maciço de solo-cimento para alvenaria deve ser no mínimo 2,0 MPa. O tijolo de 
adobe utilizado como referência obteve média de 2,5 $\mathrm{MPa}$. Os tijolos com adição de CCCM apresentaram valores médios superiores, sendo: $3 \mathrm{MPa}$; 2,9 MPA; 2,7 MPa e 2,5 MPa para os respectivos valores de adição $5 \%, 10 \%, 15 \%$ e $20 \%$.

Os tijolos adicionados de fibra do coco apresentaram resultados abaixo do mínimo exigido pela NBR 8492 (ABNT, 2012) e da média apresentada pelo adobe de referência. Os valores médios obtidos pelo adobe com fibras do coco foram $2 \mathrm{Mpa} ; 1,6$ Mpa e 1,8 Mpa para os teores de substituição de 1\%, 3\% e 5\%, respectivamente.

\subsection{Ensaio de durabilidade na presença de água}

Os resultados do ensaio de durabilidade na presença de água são apresentados no gráfico da figura 6.

\section{Figura 6 - Gráfico dos resultados do ensaio de durabilidade}

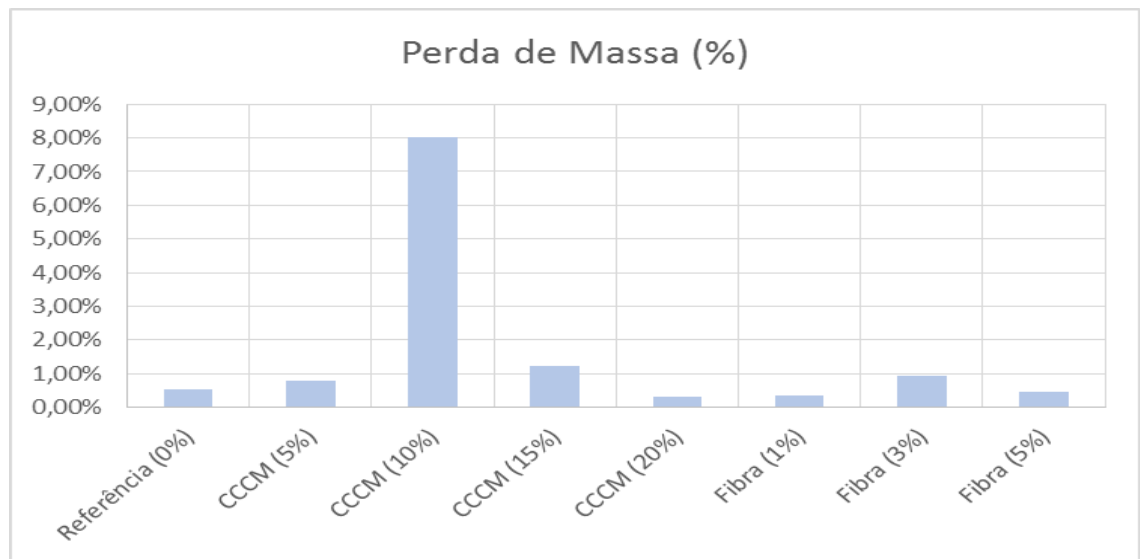

Fonte: Autores, 2013.

$\mathrm{O}$ adobe de referência obteve uma perda média de massa de $0,52 \%$, enquanto que os tijolos adicionados de CCCM apresentaram os seguintes valores $0,78 \%, 8,03 \%, 1,24 \%$ e $0,31 \%$ para os percentuais de adição de $5 \%, 10 \%, 15 \%$ e $20 \%$, respectivamente. Os tijolos adicionados de fibras do coco obtiveram uma perda média de 0,34\%, 0,92\% e $0,47 \%$ para os percentuais de adição de $1 \%, 3 \%$ e $5 \%$, respectivamente.

\section{CONSIDERAÇÕES FINAIS}

A análise do desempenho do adobe com adição de CCCM nos teores de adição de $5 \%$ e $10 \%$ apresentaram ganhos na resistência à compressão em relação aos tijolos de referência com valores médios de $18,6 \%$ e 14,34\%, respectivamente. Já no teste de durabilidade estes apresentaram piores desempenho com maior perda de massa. Os tijolos com adição de 10\% de CCCM apresentou um resultado de grande variação em relação aos demais, possivelmente por erros decorridos no ensaio. Ainda no quesito durabilidade o adobe com adição de $20 \%$ de CCCM apresentou os melhores resultados, ou seja, menor índice de perda de material, porém no ensaio de resistência à compressão, teve uma perda média de $2,71 \%$ em relação aos tijolos de referência.

Os tijolos com adição de fibras do coco apresentaram resultados abaixo do valor mínimo exigido em norma e inferiores aos valores obtidos nos blocos de referência.

No ensaio de durabilidade os tijolos com adição de fibra apresentaram bom desempenho sem grandes variações entre os índices. Em relação à média do adobe de referência, a média do adobe com $1 \%$ de fibra apresentou um ganho de $18 \%$ de conservação de 
massa. A média do adobe com $5 \%$ de fibra apresentou ganho de $0,05 \%$, já a média dos blocos de $3 \%$ apresentou resultado inferior à média dos tijolos de referência.

No processo de moldagem dos tijolos, observou-se maior dificuldade na execução dos adobes com adição de fibras, quanto maior o percentual de adição, maior a dificuldade em manusear o compósito. Os tijolos com adição de CCCM apresentaram melhor trabalhabilidade para moldagem, assim como, apresentou um endurecimento mais rápido no processo de cura.

Vale ressaltar que o ensaio de resistência à compressão foi adaptado da NBR 8492 (ABNT, 1984) para tijolos maciços de solo-cimento, pois não existe norma específica para tijolos de adobe. Em virtude de limitação técnica foram utilizados apenas dois corpos de prova para cada tipo de tijolo produzido, portanto, para futuros trabalhos recomenda-se a quantidade sugerida em norma. Outro aspecto a ser observado é a proximidade dos resultados entre os corpos de prova testados, embora, tenha-se verificado perdas e ganhos em relação à média estipulada em norma e ao adobe de referência, não foram suficientes para caracterizar que material pode oferecer melhores condições de uso, portanto, pode-se considerar que os materiais possuem desempenhos semelhantes.

No ensaio de durabilidade realizado por Ferreira e Silva (2009), os tijolos foram expostos durante alguns meses aos agentes climáticos, em ambiente natural, até observar-se a desagregação total do material do tijolo. Através da adaptação realizada neste estudo, pode-se estimar o tempo de desagregação total do material, de acordo com índices pluviométricos da região, que ocorreria em 6,41 meses para o tijolo de referência, para os tijolos com CCCM ocorreria em: 4,2 meses; 0,4 meses; 2,6 meses e 10,7 meses, respectivamente, para os tijolos com $5 \%, 10 \%, 15 \%$ e $20 \%$ de percentual de adição. Para os tijolos com fibras de coco, pode-se estimar: 9,8 meses; 3,6 meses e 7,0 meses, para os adobe com $1 \%, 3 \%$ e $5 \%$ de adição, respectivamente. Observa-se que o resultado deste ensaio é condicionado ao clima da região onde o estudo é realizado e oferece apenas uma estimativa de durabilidade do produto.

A utilização de CCCM e fibras do coco para reforçar blocos de adobe pode ser viável em comunidades rurais. A CCCM pode garantir maior resistência aos blocos e devem ser melhor protegidas do contato com água. As fibras do coco garantem menor desgaste com a presença de água. Para evitar o contato direto com as águas das chuvas, recomenda-se construções com alpendres alargados em todo o perímetro da residência, arquitetura típica das zonas rurais no Brasil, assim como, o revestimento das paredes para redução da vulnerabilidade à ação do intemperismo.

\section{REFERÊNCIAS}

ASSOCIAÇÃO BRASILEIRA DE NORMAS TÉCNICAS (ABNT). NBR- 6459: Solo Determinação do Limite de Liquidez. Rio de janeiro, 1984. . NBR- 7182: Solo - Ensaio de Compactação. Rio de Janeiro, 1986. . NBR- 7181: Solo - Análise Granulométrica. Rio de janeiro, 1984. NBR- 7180: Solo - Determinação do Limite de Plasticidade. Rio de janeiro, 1984. . NBR- 6457: Amostras de Solo - Preparação para Ensaios de Compactação e Ensaios de Caracterização. Rio de janeiro, 1984.

NBR 8492. Tijolo maciço de Solo-Cimento- Análise dimensional, determinação da Resistência à compressão e absorção de água- Método de Ensaio. Rio de Janeiro, 2012. 
NBR NM 24. Materiais Pozolânicos - Determinação do Teor de Umidade. Rio de Janeiro, 2003.

NBR 5752. Materiais Pozolânicos - Determinação de atividade pozolânica com Cimento Portland - Índice de atividade pozolânica com cimento - Método de ensaio. Rio de Janeiro, 2012.

NBR NM 248. Agregados-Determinação da composição granulométrica. Rio de Janeiro, 2012.

NBR 12653. Materiais Pozolânicos. Rio de Janeiro, 1992.

NBR NM 23. Cimento Portland e outros materiais em pó - Determinação da massa específica. Rio de Janeiro, 2001.

NM 52. Agregado miúdo - Determinação de massa específica e massa específica aparente. Rio de Janeiro 2003.

CARVALHO, R. M. Soluções para a construção de habitação em adobe a custos controlados. Tese apresentada à Universidade de Aveiro para cumprimento dos requisitos necessários à obtenção do grau de Doutor em Engenharia Civil. Aveiro. Portugal, 2012.

CORRÊA, A. et al. Avaliação das propriedades físicas e mecânicas do adobe. Ciênc. agrotec. Lavras, v. 30, n. 3, p. 503-515, maio/jun., 2006.

DEPARTAMENTO DE ESTRADAS E RODAGENS - DNER-ME 093/94: Solos Determinação da Densidade real - Método de Ensaio. DNER, 1994.

FERREIRA, S. R. SILVA, A. C. Estudo das propriedades mecânicas de adobe com adição de fibras de vegetais de coco verde. In: Encontro nacional sobre Aproveitamento de Resíduos na Construção. Feira de Santana: ENARC. 2009.

FREIRE, W. J. Tecnologias e materiais alternativos de construção. Campinas, SP: Editora da Unicamp, 2003.

FUNCEME. Gráfico de chuvas dos postos pluviométricos. Fortaleza, 2013. Disponível em:http://www.funceme.br/index.php/areas/tempo/grafico-de-chuvas-dos-postos-

pluviometricos. Acesso em maio/2013.

FUNGARO, A. F., SILVA, M. G. da. Utilização de Zeólitas Preparada a Partir de Cinza residual de Carvão como Adsorvedor de Metais em Água. Química Nova. São Paulo. 2002.

HEJAZI, S. M. et al. A simple review of soil reinforcement by using natural and synthetic fibers. Construction and Building Materials, v. 30, p.100-116, 2012

HERNANDEZ, R. et al. Cartilha de pruebas de campo para seleccion de tierras en la fabricación de adobes. México: Conescal, 1983

MARTINEZ, E. A. (Coord.). Manual para la construcion das viviendas con adobe. 1979.

MEHTA, P.K. Natural Pozzolan. In: Suplementary Cementing Materials. Ottawa: V. M. Malhotra. 1987.

MOTTA, A. L. T. S.; MACHADO, J. M.; SCOVINO, P. F. O resgate do adobe e sua adequação a necessidade de construções contemporâneas. In: $2^{\circ}$ Congresso Nacional da Construção, 2004, Cidade do Porto. CONSTRUÇAO 2004, 2004.

MOTTA, L.A.C., AGOPYAN, V. Caracterização de fibras curtas empregadas na Construção Civil. Boletim Técnico da Escola Politécnica da USP. São Paulo, 2007.

NOBRE, C.P. PINTO, D.G.L. CABRAL, A. E. B. Caracterização de Cinza de Combustão de Carvão Mineral oriunda de FGD da Usina Termelétrica Pecém. Departamento de Engenharia Civil -Universidade Federal do Ceará. 2013. (Em publicação).

OLIVEIRA, L.B. Arquitetura e Sustentabilidade: perspectivas, dificuldades e propostas. Dissertação de Mestrado. Brasília: UnB, 2003. 